\title{
Levantamento Qualitativo e Quantitativo dos Equipamentos e Estrutura do Parque do Povo, São Paulo - SP
}

Qualitative and Quantitative Survey of equipment and structure People's Park, São

Paulo-SP

Cualitativa y cuantitativa Encuesta de Equipos y estructura de Parque del Pueblo, Sao

Paulo-SP

Talita Batista dos Santos

Graduanda, UNINOVE, Brasil talitaasants@gmail.com

Milena de Moura Régis

Professora Mestre, UNINOVE, Brasil milenaregis@hotmail.com

Ana Paula do Nascimento Lamano Ferreira

Professora Doutora, GeAS-UNINOVE, Brasil apbnasci@yahoo.com.br 


\section{RESUMO}

As áreas verdes urbanas são importantes para a conservação da biodiversidade local, garantem a qualidade de vida a população urbana, além de proporcionar uma valorização paisagística e visual ao espaço. A conservação, segurança e manutenção que as áreas verdes urbanas promovem equilíbrio de convivência entre as pessoas e a natureza. Desta forma, o presente artigo objetivou levantar quanti-qualitativamente os equipamentos e a estrutura do Parque do Povo - Mario Pimenta Camargo. A coleta de dados utilizada foi baseada pelo modelo proposto por De Angelis et al. (2004). O instrumento de pesquisa auxilia na mensuração da qualidade dos equipamentos e da estrutura do parque, tornando-se uma ferramenta significativa na tomada de decisão de gestores públicos, visando melhoria do espaço. O parque possui espaços específicos para esporte, além de conjuntos temáticos com diversos exemplares arbóreos. O local não possui cabines de telefones, quiosques de alimentação e estacionamento.

PALAVRAS-CHAVE: Parques urbanos, Áreas verdes urbanas, Espaços e Equipamentos Públicos.

\section{ABSTRACT}

Urban green areas are important for the conservation of local biodiversity, guarantee the quality of life of the urban population, and provide a landscape enhancement and visual space. Conservation, security and maintenance that urban green areas promote coexistence balance between people and nature. Thus, this article aimed to raise quantitative and qualitative equipment and structure the People's Park - Mario Pimenta Camargo. Data collection used was based on the model proposed by De Angelis et al. (2004). The research instrument assists in measuring the quality of the equipment and structure of the park, making it a significant tool in the decision making of public managers, aimed at improving the space. The park has specific spaces for sport, as well as themed sets with various arboreal specimens. The site does not have phone booths, food kiosks and parking.

KEYWORDS: Urban Parks, Urban Green Areas, Spaces and Public Equipment.

\section{RESUMEN}

Zonas verdes urbanas son importantes para la conservación de la biodiversidad local, garantizan la calidad de vida de la población urbana, y proporcionan una mejora del paisaje y el espacio visual. Conservación, seguridad y mantenimiento que las áreas verdes urbanas promueven el equilibrio convivencia entre las personas y la naturaleza. Por lo tanto, este artículo como objetivo elevar equipos cuantitativa y cualitativa y la estructura del Parque del Pueblo - Mario Pimenta Camargo. La recolección de datos utilizada se basó en el modelo propuesto por De Angelis et al. (2004). El instrumento de investigación ayuda a medir la calidad de los equipos y la estructura del parque, por lo que es una herramienta importante en la toma de decisiones de los gestores públicos, destinados a mejorar el espacio. El parque cuenta con espacios específicos para el deporte, así como conjuntos temáticos con diversos especímenes arbóreos. El sitio no tiene cabinas telefónicas, kioscos de comida y aparcamiento.

PALABRAS CLAVE: Los parques urbanos, zonas verdes urbanas, Espacios e Instalaciones Públicas. 


\section{INTRODUÇÃO}

O avanço no processo de urbanização e crescimento de cidades está transformando a paisagem em ritmo acelerado, pressionando e trazendo grandes problemas ao ambiente. 0 desenvolvimento urbano não planejado afeta o espaço físico das cidades, contribuindo para o desequilíbrio ambiental e na qualidade de vida de suas populações. Essas transformações nas cidades trazem uma preocupação com o planejamento e gestão pública a partir da compreensão da diversidade dos aspectos do espaço urbano com a dimensão socioambiental (BARGOS; MATIAS, 2011).

Nas últimas décadas, tem-se discutido com mais ênfase os problemas ambientais, tornando-se uma temática obrigatória para o cotidiano. As áreas verdes tornaram-se então um dos principais ícones de defesa do meio ambiente, por conta de sua degradação e pelo seu pequeno espaço que é destinado aos centros urbanos (LOBODA; DE ANGELIS, 2005).

Segundo Feiber (2004), as áreas verdes possuem importância funcional no metabolismo da cidade, atuando no conjunto de fenômenos físicos e químicos necessários a vida, como a redução da poluição e a ciclagem de nutrientes (FERREIRA et al., 2014), além de garantir a preservação e abrigo à fauna e flora existente. Loboda e De Angelis (2005) relatam sobre a importância das áreas verdes urbanas para a qualidade de vida, agindo simultaneamente sobre o lado físico e mental do homem, tornando-se imprescindível para o bem-estar da população (BOVO; CONRADO, 2012).

Os inúmeros benefícios que as áreas verdes urbanas proporcionam à sociedade são disponibilizados principalmente pelos parques públicos. Dorigo e Ferreira (2015) apud Bargos e Matias (2011) consideram os parques urbanos como "áreas verdes de domínio público com função ecológica, estética e de lazer". Esses espaços estão relacionados a gestão ambiental e a qualidade de vida das populações, por meio dos serviços ambientais que são prestados, como a preservação de recursos naturais, a socialização e o aprendizado (CARDOSO; VASCONCELLOS SOBRINHO; VASCONCELLOS, 2015).

O planejamento, a conservação e a manutenção de espaços verdes urbanos interferem em seu desempenho funcional para alcançar maior eficiência possível, influenciando diretamente na qualidade de vida da população e contribuindo para a amenização das consequências negativas que o avanço acelerado da urbanização trouxe ao meio ambiente (BARGOS; MATIAS; OTHERS, 2012). Diante disso, o Parque do Povo - Mario Pimenta Camargo foi escolhido para o desenvolvimento deste trabalho devido sua importância socioambiental que ele representa na região onde foi implantado. $O$ parque foi inaugurado recentemente (em 28 de setembro de 2008), tornando-se um importante espaço para a avaliação da conservação e manutenção de áreas verdes urbanas da cidade de São Paulo, pois seu planejamento, gerenciamento e fiscalização são mantidos por meio de políticas públicas entre gestores municipais e representantes da sociedade civil. 


\section{OBJETIVO}

O presente trabalho teve como objetivo realizar o levantamento da infraestrutura do Parque Mario Pimenta Camargo, com o intuito de informar quais equipamentos o parque urbano pode oferecer aos frequentadores.

\section{METODOLOGIA}

\section{ÁREA DE ESTUDO}

O estudo foi realizado no Parque do Povo (Mario Pimenta Camargo), localizado no Bairro Itaim Bibi, na cidade de São Paulo, próximo as avenidas Cidade Jardim, Henrique Schaumann e Nações Unidas. O parque foi instalado numa área que pertencia a CEF (Caixa Econômica Federal) e ao INSS (Instituto Nacional de Seguro Social). Durante duas décadas, diversas agremiações esportivas ocuparam o local, até que em 2006 a Prefeitura conseguiu a concessão do espaço. Sua área é de $133.547 \mathrm{~m}^{2}$ e atualmente o espaço é propriedade da Construtora WTORRE Empreendimentos e da Prefeitura Municipal de São Paulo.

O Parque do Povo está localizado em uma área nobre na região oeste da cidade de São Paulo. Possui fácil acesso a diversos estabelecimentos comerciais, centros empresariais e residenciais, além de, no entorno do parque serem encontrados pontos de taxi e de ônibus, bem como a estação Cidade Jardim da CPTM (Companhia Paulista de Trens Metropolitanos). O parque funciona diariamente das $6 \mathrm{~h}$ às $22 \mathrm{~h}$, e sua infraestrutura possui complexos esportivos, quadras poliesportivas, campo de futebol gramado, ciclovia, pista de caminhada, aparelhos de ginastica para a terceira idade e atividades permanentes como por exemplo o grupo de caminhada e o de Tai Chi Pai Lin. O parque também dispõe de roteiros botânicos, como por exemplo o Jardim dos Sentidos, onde os frequentadores podem tocar, cheirar e morder folhas de espécies vegetais.

Segundo a Secretaria Municipal do Verde e do Meio Ambiente da Prefeitura de São Paulo, foram registradas no parque 32 espécies de plantas, dentre elas 2 espécies ameaçadas de extinção, a Grumixama (Eugenia brasiliensis) e o Pau-Brasil (Caesalpinia echinata), além de 37 espécies de aves típicas de ambientes abertos, como o quero-quero, avoante, rolinha, asabranca, beija-flor-tesoura, pica-pau-do-campo, suiriri-cavaleiro, sabiá-do-campo, tico-tico, maracanã-nobre, tuim, sanhaçu-do-coqueiro, ferreirinho-relógio, alegrinho e pitiguari. 
Figura 1. Vista Superior do Parque Mario Pimenta Camargo, popularmente conhecido como Parque do Povo.

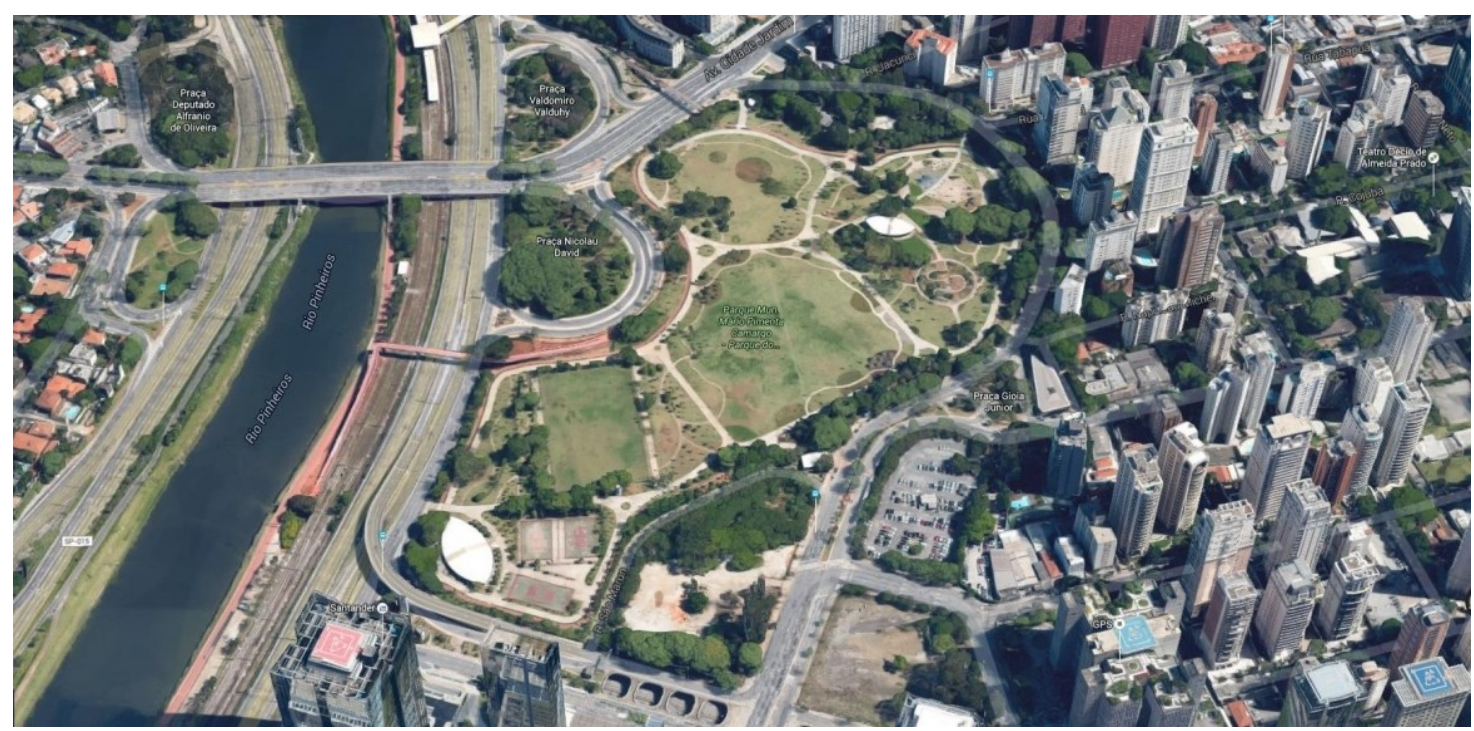

Fonte: Google Earth, 29.04.2016

\section{COLETA E ANALISE DE DADOS}

Para o desenvolvimento desta pesquisa, os dados coletados foram baseados em fichas propostas por De Angelis et al. (2004). As fichas foram preenchidas durante as visitas ao parque, as quais ocorreram nos dias 05 de março de 2016 e 16 de abril de 2016.

O parque foi categorizado a partir do levantamento qualitativo e quantitativo por meio do método desenvolvido por De Angelis et al. (2004), adaptado ao Parque do Povo (Mario Pimenta Camargo). Foram observados a estrutura existente no local, assinalando a presença ou ausência de equipamentos e estruturas. Ainda sob o método dos autores, foram levantadas a quantidade de cada estrutura existente, além da avaliação de suas condições no ambiente. As fichas foram preenchidas de acordo com a observação do pesquisador, em relação a quantidade e qualidade dos equipamentos existentes no parque.

\section{RESULTADOS E DISCUSSÃO}

O parque possui boa iluminação, alternando entre pontos altos, localizados nos gramados centrais do parque e nas quadras poliesportivas, e pontos baixos, rodeando as pistas de caminhada e ciclovias, conforme demonstra a Tabela 1. 
Tabela 1. Levantamento quali-quantitativo dos equipamentos e estruturas existentes no Parque do Povo.

\begin{tabular}{lcc}
\hline \multicolumn{1}{c}{ EQUIPAMENTOS/ESTRUTURAS } & QUANTIDADE & QUALIDADE \\
\hline 1.Bancos - material: madeira e concreto & 97 & BOM \\
2. Iluminação alta e baixa & 156 & BOM \\
3. Lixeiras & 72 & ÓTIMO \\
4. Sanitários & 4 & ÓTIMO \\
5. Bebedouros & 6 & ÓTIMO \\
6. Caminhos - material: concreto & 3 & BOM \\
7. Obra de arte: & 2 & BOM \\
8. Ponto de ônibus & 2 & BOM \\
9. Ponto de táxi & 1 & BOM \\
10. Quadra esportiva & 3 & ÓTIMO \\
11. Para prática de exercícios físicos & 2 & ÓTIMO \\
12. Para terceira idade & 2 & ÓTIMO \\
13. Parque infantil & 1 & ÓTIMO \\
14. Identificação & 2 & BOM \\
15. Edificação institucional & 2 & ÓTIMO \\
\hline
\end{tabular}

Fonte: O autor, 2016

Os bancos estão distribuídos em toda sua extensão, localizados principalmente nos arredores das pistas de caminhada, ciclovias, playgrounds e quadras. Possuem bancos de madeira e de concreto, e estão bem conservados, atendendo sua funcionalidade. Rodeados pelos bancos em lugares estratégicos, foram localizados 9 bituqueiras, que são aparatos destinados ao descarte de bitucas de cigarro. Assim como os bancos e a iluminação, as lixeiras estão distribuídas em toda a extensão do parque. A grande maioria apresenta um bom estado, e foram localizados três tipos de lixeiras: Lixeiras destinadas para o descarte de dejetos de animais, lixeiras com segmentos informados como reciclável e não reciclável, e lixeiras com segmentação de materiais recicláveis (papel, plástico, metais, vidro e lixo não orgânico).

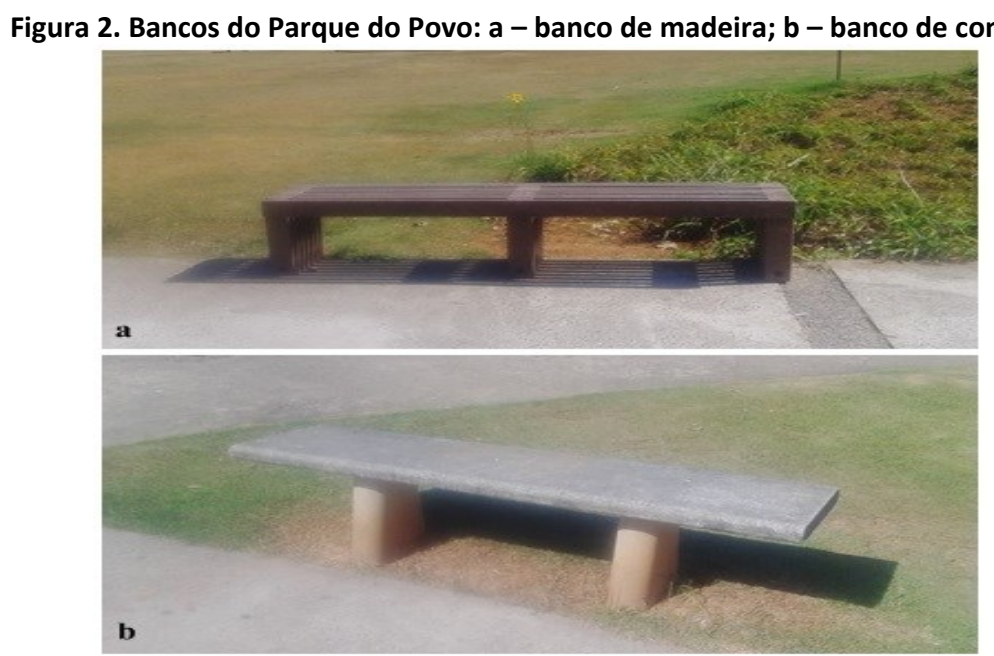

Fonte: $\mathrm{O}$ autor, 2016

Os sanitários do parque estão em bom estado, nestes são encontrados armários com cadeados onde os frequentadores podem guardar seus pertences enquanto praticam suas atividades 
físicas. Nos banheiros do parque também há presença de plantas, que recebem luz solar, ou seja, parte dos tetos dos banheiros são abertos para que a vegetação receba diretamente a radiação solar que ali incide.

Figura 3. Equipamentos do Parque do Povo: a - lixeiras recicláveis; $b$ - iluminação baixa, lixeira e banco; $\mathrm{c}$ - bebedouro; $\mathbf{d}$ - lixeira

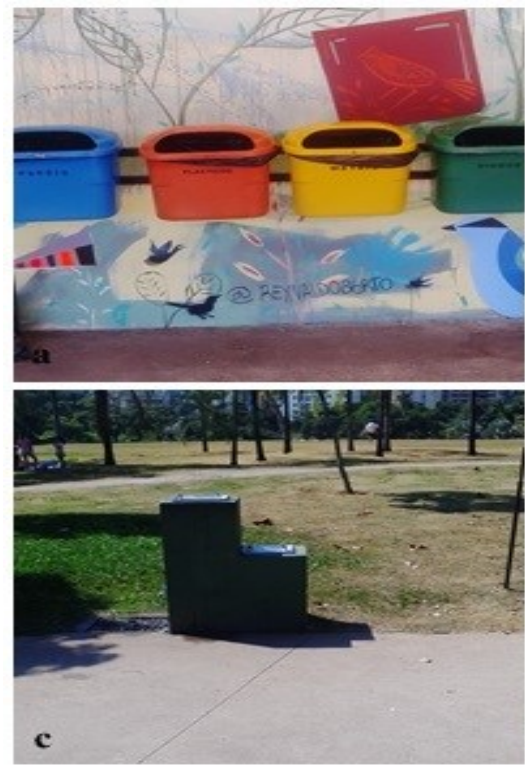

Fonte: O autor, 2016

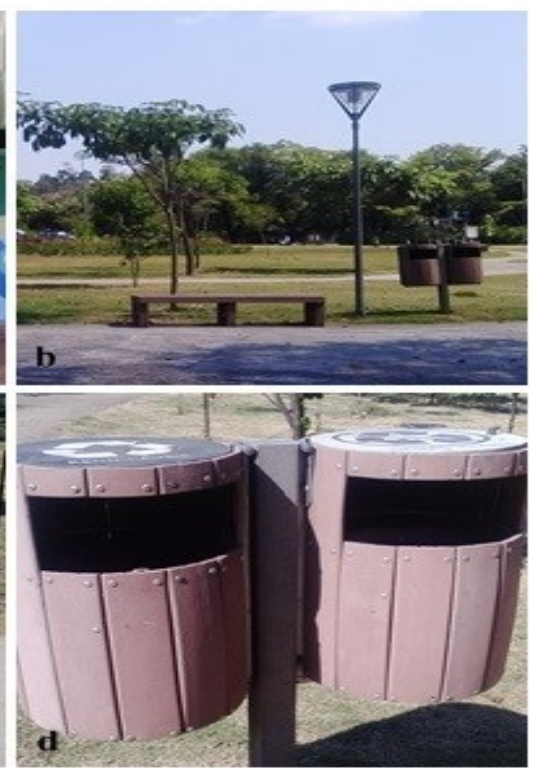

d 
Figura 4. Infraestrutura do Parque do Povo: a - aparelho de ginastica; $b$ - aparelho de ginastica para a terceira idade; c-Administração; $d$ - playground

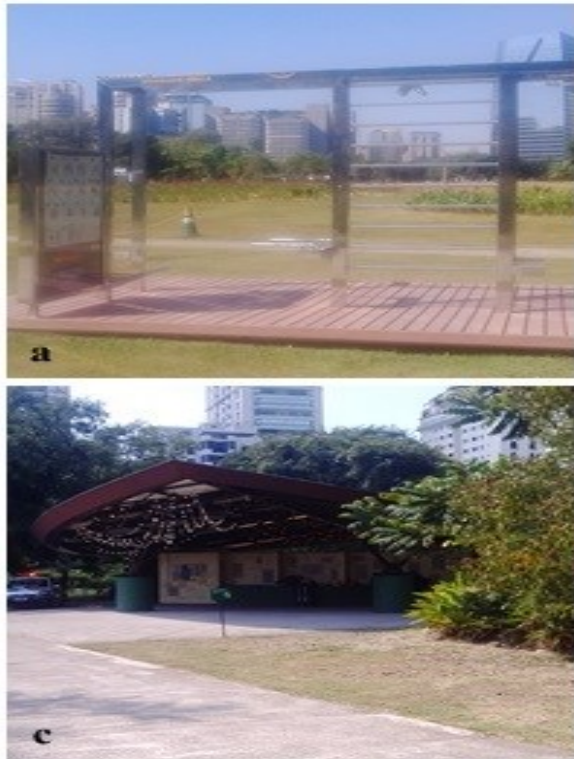

Fonte: $\mathrm{O}$ autor, 2016

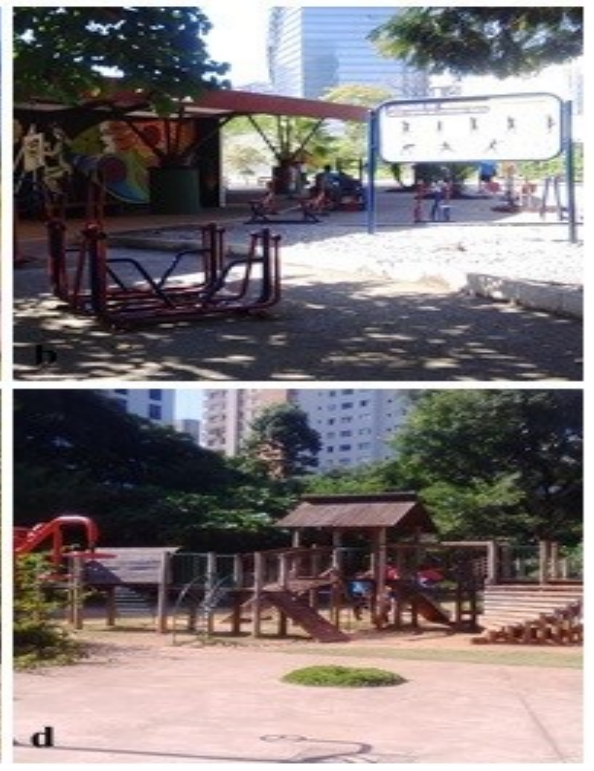

d

No complexo esportivo do parque, as quadras poliesportivas possuem marcação especial para esportes paraolímpicos, e um campo de futebol gramado. Estão em bom estado, possuem iluminação alta e seu piso está pintado e bem conservado. Próximos a esse complexo e nos demais arredores do parque, foram localizados bebedouros, todos em funcionamento. Cabe ressaltar que os bebedouros são adaptados para cadeirantes e também para os animais.

O parque possui pista de skate e patins, de caminhada/corrida e ciclovias. Seu piso é impermeável e o material constituinte é o concreto reaproveitado do entulho de construção civil das edificações que existiam anteriormente no local. A pista de caminhada/corrida está localizada em todos os espaços do parque, e seu entorno apresenta vegetação, porém com um baixo sombreamento, devido a diminuta área vegetativa no parque. A pista de skate e patins está localizada próximo ao complexo esportivo do parque, e a ciclovia no entorno geral do local, com duas entradas e saídas, que dão acesso a ciclovias externas das avenidas próximas ao parque.

Em volta do parque, foram localizados dois pontos de ônibus e um ponto de taxi, facilitando o acesso ao local. O parque não possui estacionamento.

O parque possui dois prédios de apoio à administração, onde estão localizados os banheiros e a sede administrativa do local. Sua construção possui ventilação natural e prioriza a luz do dia, reduzindo o uso de energia. No entorno dos prédios possuem murais com informativos gerais sobre as normas do parque, horários de atendimento, contato com a administração e atividades culturais e esportivas.

Em dois pontos do parque foram localizadas duas esculturas esculpidas em bronze fundido e patinado. A escultura "Homem na Chuva" de Christina Motta (São Paulo, 1944) e uma peça de Florian Raiss denominada como "Os Quadrupedes". Não foram localizados no parque 
telefones públicos, palcos, chafariz e nascentes, bancas de revistas para venda, quiosques de alimentação e templos religiosos.

Figura 5. Obras de arte do Parque do Povo: a - Homem na Chuva; b - Os Quadrupedes

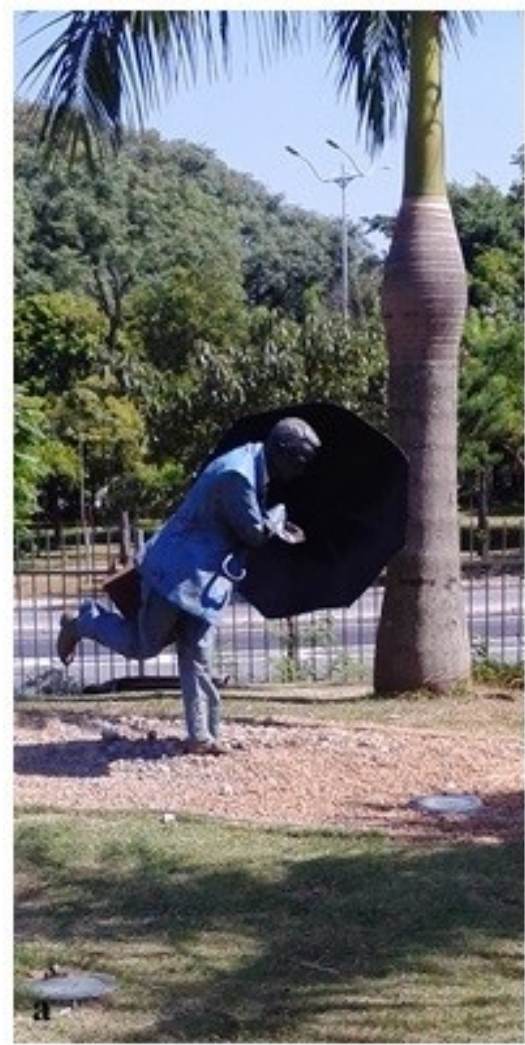

Fonte: O autor, 2016

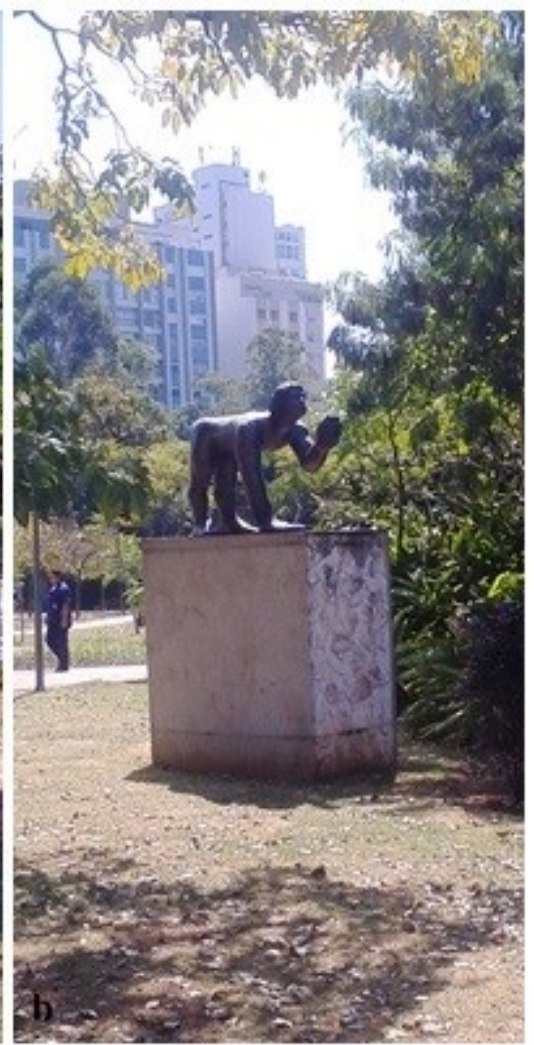

(

\section{CONCLUSÃO}

O Parque do Povo está localizado em uma região nobre de São Paulo, com fácil acesso a diversos meios de transporte, além de uma ampla estrutura de estabelecimentos empresariais, comerciais e residenciais, onde atraem visitantes que trabalham ou moram próximos ao local. Foi observado a presença de vigias durante o dia, o que inspira segurança e tranquilidade aos frequentadores do parque.

O local possui ótima infraestrutura quantitativa e qualitativa esportiva, desta forma, observase que o parque foi destinado ao público que busca praticar atividades físicas, como o futebol, os circuitos de ginastica/CrossFit, corridas/caminhadas, yoga, massagem, artes marciais, entre outras práticas, mas também se observa a presença de frequentadores com crianças que fazem uso de playgrounds, de idosos que utilizam as academias da terceira idade. Devido ao piso plano, nota-se também a presença de visitantes com animais para passeios. Observou-se também a presença de frequentadores utilizando os espaços mais sombreados para pratica de piquenique e de descanso. 
E em toda a área do Parque são encontradas placas informativas identificando as espécies de plantas, os equipamentos e infraestrutura do local (pistas, banheiros, bebedouros, quadras, administração, entre outros), além de informativos sobre as normas de cada ambiente do parque. Cabe informar que o parque não possui pontos de venda de alimentos, telefones públicos e estacionamento. Apesar da diversidade de espécies de arvores exóticas, nativas frutíferas, madeiras nobres e trepadeiras, foi observado pouca área arbórea densa, o que torna este espaço uma área aberta e com pouca sombra.

\section{AGRADECIMENTO}

A realização do trabalho que conduziu este artigo foi possível devido a colaboração do Corpo Docente da Universidade Nove de Julho e do Programa de Gestão Ambiental e Sustentabilidade (GeAS), às quais me dirijo meu sincero agradecimento pela orientação, incentivo e suporte técnico para o desenvolvimento desta pesquisa.

\section{REFERÊNCIAS BIBLIOGRÁFICAS}

BARGOS, D. C.; MATIAS, L. F. Áreas verdes urbanas: um estudo de revisão e proposta conceitual. Revista da Sociedade Brasileira de Arborização Urbana, v. 6, n. 3, p. 172-188, 2011.

BARGOS, D. C.; MATIAS, L. F.; OTHERS. Mapeamento e análise de áreas verdes urbanas em Paulínia (SP): estudo com a aplicação de geotecnologias. Sociedade \& Natureza, v. 24, n. 1, p. 143-156, 2012.

BOVO, M. C.; CONRADO, D. O parque urbano no contexto da organização do espaço da cidade de Campo Mourão (PR), Brasil. Caderno Prudentino de Geografia, v. 1, n. 34, p. 50-71, 2012.

CARDOSO, S. L. C.; VASCONCELLOS SOBRINHO, M.; VASCONCELLOS, A. M. DE A. Gestão ambiental de parques urbanos: o caso do Parque Ecológico do Município de Belém Gunnar Vingren. Urbe. Revista Brasileira de Gestão Urbana, v. 7, n. 1, p. 74-90, 2015.

DE ANGELIS, B. L. D.; CASTRO, R. M. DE; DE ANGELIS NETO, G. Metodologia para levantamento, cadastramento, diagnóstico e avaliação de praças no Brasil. Engenharia Civil, v. 4, n. 1, p. 57-70, 2004.

DORIGO, T. A.; LAMANO-FERREIRA, A. P. N. Contribuições da Percepção Ambiental de Frequentadores Sobre Praças e Parques no Brasil (2009-2013): Revisão Bibliográfica. Revista de Gestão Ambiental e Sustentabilidade-GeAS, v. 4, n. 3, p. 31-45, 2015.

FEIBER, S. D. Áreas verdes urbanas: imagem e uso - o caso do passeio público de Curitiba-PR. Raega-O Espaço Geográfico em Análise, v. 8, 2004.

FERREIRA, M. L. et al. Litter fall production and decomposition in a fragment of secondary Atlantic Forest of São Paulo, sp, southeastern Brazil. Revista Árvore, v. 38, n. 4, p. 591-600, 2014.

LOBODA, C. R.; DE ANGELIS, B. L. D. Áreas verdes públicas urbanas: conceitos, usos e funções. Ambiência, 2005. 